Universidad de Lima

Facultad de Ciencias Empresariales y Económicas

Carrera de Economía

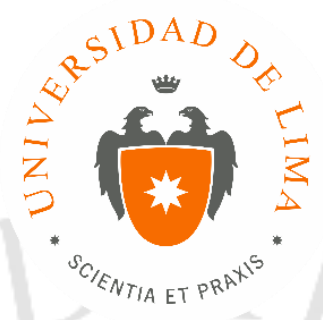

\title{
ANÁLISIS DE LA COMPETENCIA Y CONCENTRACIÓN DEL SISTEMA BANCARIO EN EL PERÚ 2012-2017
}

Trabajo de suficiencia profesional para optar el Título Profesional de Economista

Sustentación de caso

Alonso Tejeda Zamora

Código 20122252

Asesor

Napoleón Ambrocio Barrios

Lima - Perú

Diciembre de 2018 


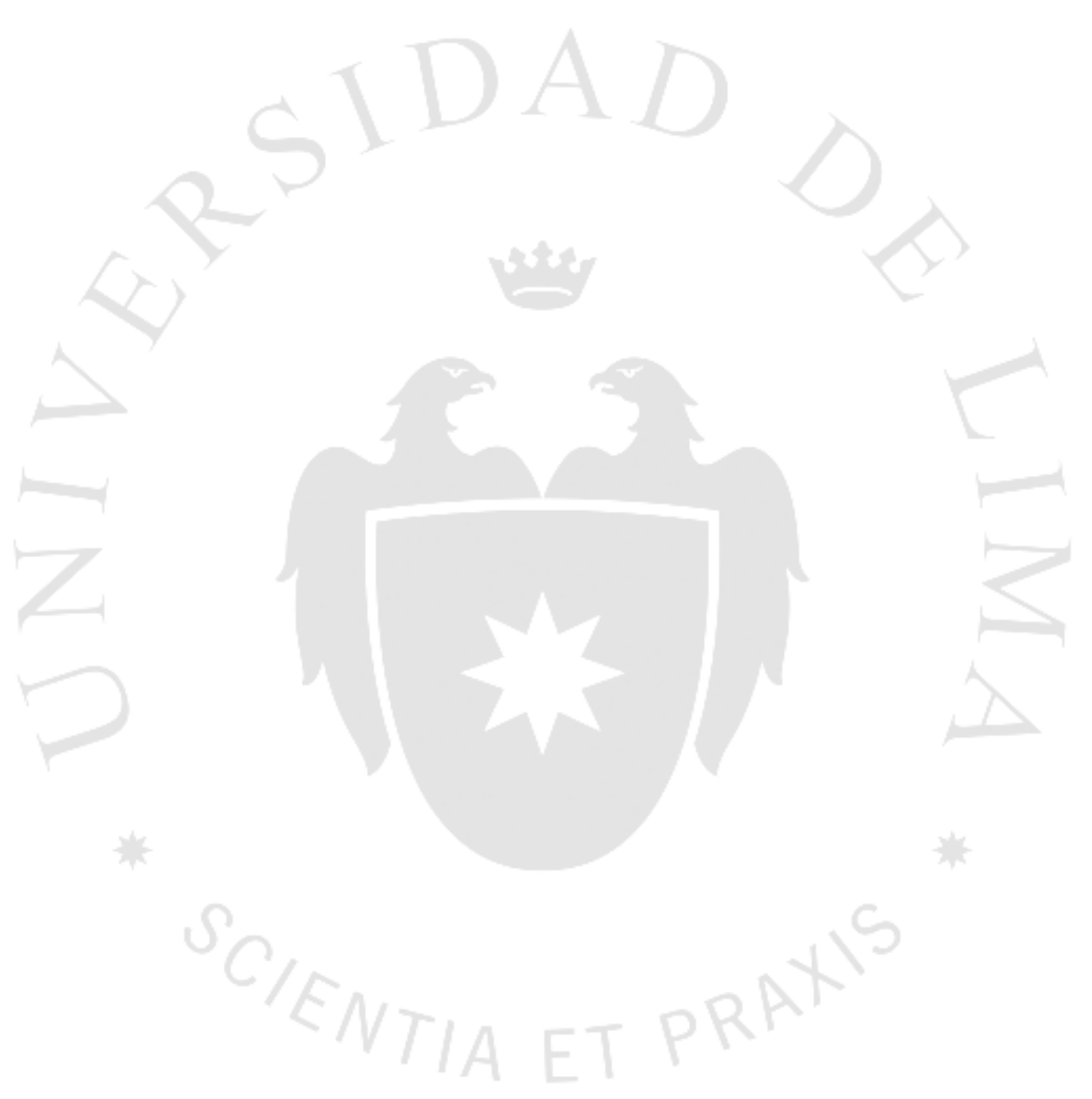




\section{ANÁLISIS DE LA COMPETENCIA Y CONCENTRACIÓN DEL SISTEMA BANCARIO EN EL PERÚ 2012-2017}




\section{TABLA DE CONTENIDO}

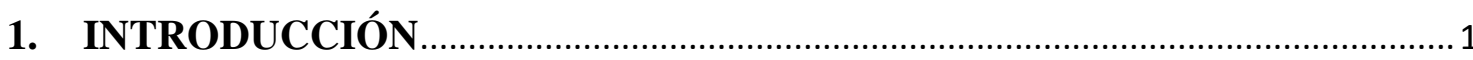

2. OBJETIVOS

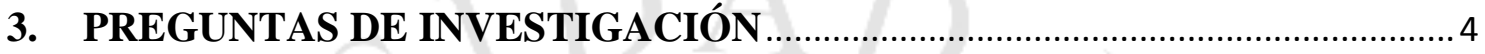

4. METODOLOGÍA DE RECOLECCION DE LA INFORMACIÓN ...................5

5. METODOLOGÍA DE ANÁLISIS DE LA INFORMACIÓN .............................. 7

5.1 Análisis de la teoría económica e información estadística......................................

5.1.1 Impacto de la concentración al consumidor .................................................... 12

5.1.2 Crecimiento de las Cajas de Ahorro y Crédito en el sistema financiero..............15

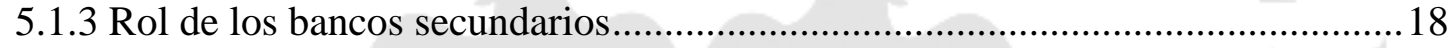

5.2 Análisis econométrico de la información........................................................22

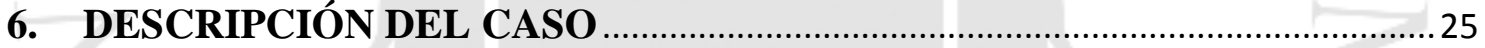

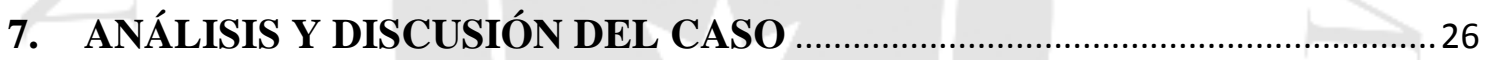

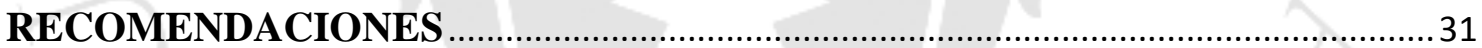

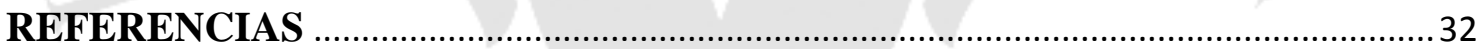




\section{ÍNDICE DE TABLAS}

Tabla 5.1 Composición de los créditos en el sistema financiero a junio de $2018 \ldots \ldots \ldots \ldots \ldots \ldots . . . . .8$

Tabla 5.2 Activos de sistema financiero en millones de soles ............................................. 16

Tabla 5.3 Comparación tasas activas de bancos vs CAC …................................................... 17

Tabla 5.4 Comparación tasas pasivas de bancos vs CAC …................................................ 17

Tabla 5.5 Participación créditos directos............................................................................ 19

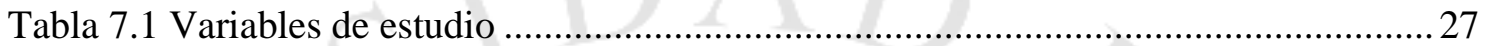

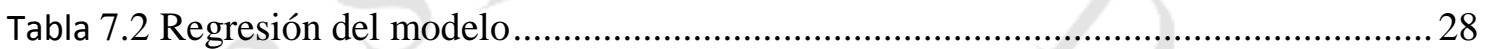




\section{ÍNDICE DE FIGURAS}

Figura 5.1 Evolución de la cartera de colocaciones según tipo de crédito..............22

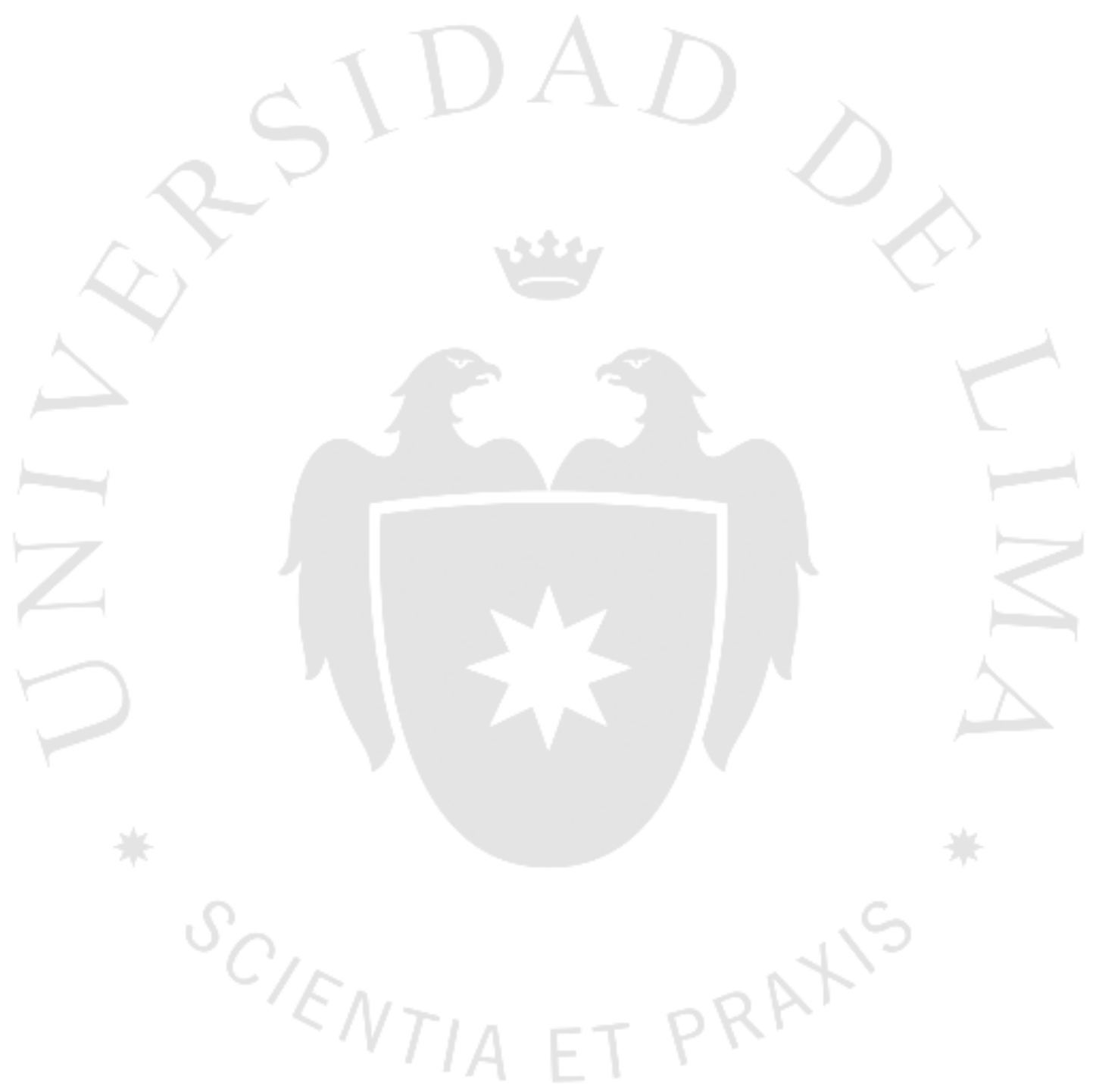




\section{INTRODUCCIÓN}

Desde principios del siglo XX, el sistema bancario y financiero del Perú siempre ha tenido una importancia relativa dentro de la economía del país y la cual ha venido evolucionando de la misma manera a través de la historia. Los primeros bancos aparecieron dentro del periodo de tiempo denominado "Bonanza del Guano" a raíz de la capitalización que se estaba produciendo por las utilidades que se generaban y la necesidad del manejo de depósitos y créditos a las distintas industrias en crecimiento dentro del territorio peruano. Conforme fue avanzando el siglo, la creación del Banco de la Nación, del Banco Central de Reserva y la introducción de bancos nacionales y extranjeros comenzó a matizar el sistema bancario peruano.

Durante el primer gobierno de García Pérez en la década de los 80, la economía del Perú estaba entrando en un estado de crisis sin precedentes que llevó a tomar la decisión de estatizar el sistema bancario. Lamentablemente, este accionar no trajo consigo sino una serie de revueltas y protestas por parte del sector privado como también de los depositantes que buscaban de forma desesperada retirar su dinero para que este no caiga en manos de un estado con una clara deficiencia en el manejo económico del país.

Ya en la década de los noventas, dicha imposición del gobierno anterior fue derogada y una serie de normas y cambios dentro del modelo económico a seguir y la política economía del Perú, permitió fortalecer la banca e incluso el ingreso de nuevas instituciones bancarias extranjeras. La eliminación de los controles cambiarios o fijación de un tipo de cambio dólar, libertad para el manejo de las tasas activas y pasivas, como también la redefinición del rol que desemplea el banco Central de Reserva del Perú, el banco de la Nación y la Corporación Financiera de Desarrollo (COFIDE). Todas estas reformas e ingresos de nuevos agentes al sistema financiero, trajo consigo la creación de una banca múltiple mucho más solida que su contraparte en la década de los 80 y más allá de unas fusiones bancarias y otras complicaciones a fines de los 90 (debido a la crisis asiática global) ha logrado consolidarse y seguir fortaleciéndose hasta la segunda década del siglo XXI.

En la actualidad, el sistema de banca múltiple del Perú esta conformado por 16 bancos, nacionales y extranjeros los cuales forman parte del sistema financiero del país al igual que las instituciones financieras, las Cajas de Ahorro y Crédito, las cooperativas 
de ahorro y las entidades de regulación y supervisión. Sin embargo, es importante agregar que, dentro del sistema bancario de nuestro país, alrededor del 82\% del total de depósitos, créditos colocados y patrimonios se encuentran repartidos únicamente entre 4 bancos principales: Banco de Crédito del Perú, Banco BBVA Continental, Banco Scotiabank e Banco Interbank.

Es importante analizar y estudiar que tanto impacta la concentración del sistema bancario en términos de competencia de cara al consumidor; si esta concentración ha traído consigo mejores tasas de interés (tanto pasivas para los depósitos como activas para las colocaciones), mejores condiciones crediticias y flexibilidades para ingresar al sistema entre otras consecuencias. Al mismo tiempo sería interesante observar el efecto colateral que tendría no solamente con el accionar del resto de banco con menor participación en el mercado, sino también de las entidades financieras alternativas que componen el universo financiero del país.

Mediante el presente estudio de caso, se tiene como objetivo el análisis de la alta concentración del sistema bancario en el Perú durante los periodos del 2012 al 2017 y comprobar si dicho fenómeno trae consigo una mejor situación de bienestar de cara a los participantes del sistema financiero del País. Asimismo, evaluar el impacto que tiene la alta concentración con el crecimiento de las Cajas de Ahorro y Crédito como alternativas de ahorro para los agentes económicos. Finalmente, analizar el rol que desempeñan los bancos que conforman el $8 \%$ aprox. restante de la banca múltiple del país. 


\section{OBJETIVOS}

Para el presente trabajo de investigación se tendrán los siguientes objetivos; principales y secundarios, planteados:

- Objetivo Principal: Comprobar si la alta concentración en colocaciones del sistema bancario en el Perú ha traído consigo una mayor o menor competencia entre sus partícipes.

- Objetivo Secundario: Evaluar el impacto al consumidor de la alta concentración del sistema bancario en el Perú.

- Objetivo Secundario: Analizar el impacto de la alta concentración con el crecimiento de las Cajas de Ahorro y Crédito como opción a la banca múltiple para los agentes económicos.

- Objetivo Secundario: Evaluar el rol del resto de bancos que conforman la banca múltiple y que no se encuentran dentro de la masa concentrada. 


\section{PREGUNTAS DE INVESTIGACIÓN}

- ¿La alta concentración del sistema bancario en las colocaciones al mercado, trae consigo una mayor competitividad entre sus pares?

- Dada la alta concentración del sistema bancario en el Perú, ¿el consumidor se puede ver beneficiado de este fenómeno?

- ¿El Crecimiento importante de las instituciones financieras alternativas, por ejemplo, las Cajas de Ahorro y Crédito es una consecuencia de la alta concentración en el sistema bancario?

- ¿Como manejan la concentración del mercado los otros bancos que se encuentran en el Perú? ¿Qué rol cumplen? 


\section{METODOLOGÍA DE RECOLECCION DE LA INFORMACIÓN}

En el presente trabajo se realizará una investigación sobre la concentración del sistema bancario y la competitividad que este genera dentro de la banca múltiple en el sistema financiero peruano. Para ello, se empleará tanto data mensual de los periodos 2012 a 2017 para el modelo econométrico a desarrollar, como también información estadística e informativa complementaria para poder dar un mayor alcance de la situación actual del sistema financiero.

Para poder comprobar el objetivo principal del presente estudio de caso se evaluará la influencia que tienen las tasas de interés de los bancos que componen el sistema de banca múltiple peruano con la cantidad de colocaciones por banco realizadas dentro del periodo de estudio. La metodología utilizada será a través de un Mínimo Cuadrado Ordinario.

Dicha información será extraída de los reportes mensuales que son colgados dentro de la página web de la SBS. De esta misma fuente de información, se estará compilando la información sobre las colocaciones totales por banco acumuladas dentro del periodo de investigación determinado. Asimismo, se está utilizando la serie estadística de la data sobre tasas activas para préstamos en moneda nacional de la página del Banco Central de Reserva del Perú para las variables independientes del modelo econométrico. Sin embargo, al momento de realizar la presente investigación la portal del BCR sólo contenía datos desde septiembre 2016 a Julio 2018, por lo que se ha tenido que complementar la información con datos de la SBS en su reporte diario de tasas activas. Para ello, se procedió a realizar un ponderado mensual de las tasas activas diarias de los bancos desde enero de 2012 a diciembre del 2017.

Asimismo, para poder realizar la explicación del caso y responder las preguntas de investigación planteadas anteriormente, se ha tomado en cuenta diversos trabajos de realizado por investigadores en el mismo tema o con relevancia en ello. Dichos trabajos de investigación se encuentran de libre acceso en internet en las páginas web de las universidades que lo publicaron dentro de su reservorio de investigaciones entre otras fuentes. 
De igual manera, las citas a algunas noticias que se utilicen para fundamentar la teoría presentada en el presente trabajo serán proporcionada a través de las páginas web de algunos diarios que recopilen información de terminología o en entrevistas a personas de relevancia. 


\section{METODOLOGÍA DE ANÁLISIS DE LA INFORMACIÓN}

\subsection{Análisis de la teoría económica e información estadística}

Para poder dar una explicación al problema de investigación del presente estudio de caso, se realizará un análisis cuantitativo y cualitativo de la información encontrada en referencia al tema de investigación.

Para comenzar, al observar el sistema financiero del Perú, es importante recordar que está conformado por instituciones encargadas de captar, administrar y canalizar recursos de los agentes económicos superavitarios hacia los agentes económicos deficitarios, los cuales se encuentran bajo regulación de la Superintendencia de Banca, Seguros y AFP o SBS (Echevarría \& milagro, 2016).

A junio 2018, el sistema financiero está compuesto por 55 empresas: 16 entidades conforman la banca múltiple, 11 son empresas financieras y 27 son empresas microfinancieras no bancarias (Cajas Municipales, Cajas Rurales, Edpyme) y 2 empresas de arrendamiento financiero. Asimismo, el saldo de los créditos directos asciende a S/299 173 millones (US\$91 434 millones). lo cual representa un crecimiento de $10.04 \%$ en activos entre junio 2017 y junio 2018 (Superintendencia de Banca, Seguros y AFP, Evolución del Sistema Financiero, 2018).

Asimismo, la distribución por tipo de los créditos en el Perú tiene la siguiente distribución en su cartera: 
Tabla 5.1

Composición de los créditos en el sistema financiero a junio de 2018

\begin{tabular}{|c|c|c|}
\hline$\underline{\text { Sector }}$ & Saldo en miles de soles & Participación \\
\hline Banca Corporativo & 65,898 & $22.0 \%$ \\
\hline Gran Empresa & 42,264 & $14.1 \%$ \\
\hline Mediana Empresa & 44,672 & $14.9 \%$ \\
\hline Pequeña Empresa & 27,288 & $9.1 \%$ \\
\hline Microempresa & 10,461 & $3.5 \%$ \\
\hline Consumo & 63,392 & $21.2 \%$ \\
\hline Hipotecario & 45,198 & $15.1 \%$ \\
\hline
\end{tabular}

Fuente: Superintendencia de Banca, Seguros y AFP, SBS (2018)

Elaboración propia.

La banca múltiple como tal ha ido evolucionando de forma continua en las últimas décadas conforme la economía del Perú se ha ido reactivando pasada la crisis de finales de los años ochenta. Esta, a través de distintas adquisiciones y fusiones que se dieron desde principios de los 90 cuando se realizó el cambio de modelo económico a seguir, ha llegado ahora a ser integrada por 16 bancos, tanto nacionales como extranjeros. Los bancos que la comprenden en la actualidad son los siguientes: Banco de Crédito del Perú, Banco Continental, Scotiabank Perú, Interbank, B. Interamericano de Finanzas, Mibanco, Banco Pichincha (ex Banco Financiero), Banco GNB, Banco Santander Perú, Banco Falabella Perú, Citibank, Banco Ripley, Banco de Comercio, Banco Cencosud, Banco Azteca Perú, Banco ICBC. Es importante mencionar que se esta tomando en cuenta únicamente entidades financieras privadas más no algunos bancos de orden estatal como Agrobanco o el Banco de la Nación para especificar la investigación de la concentración que genera la banca privada en el sector.

El sistema financiero, al igual que el resto de los sectores dentro de la economía de un país, tiene la posibilidad de tener las denominadas "fallas de mercado" que deben ser atendidas mediante un ente regulador. Estas fallas pueden ser por: Abuso de poder de dominio, la presencia de externalidades o problemas de información asimétrica por alguno de los bienes que estos tengan. Por lo tanto, las instituciones regulatorias tienen como visión no solamente intentar "reparar" dichas fallas de mercado que puedan aparecer en un mercado, sino también velar por el bienestar de los agentes económicos y 
brindarle un mejor servicio más allá de una tasa de costo más baja (o alta en términos de depósitos). Como menciona Tejada, Morón y Villacorta (2010):

No es lo mismo tener un depósito en una institución financiera que no cuenta con una gran infraestructura de sucursales y puntos de atención que otra que si los ofrece. Al consumidor no sólo le interesa la tasa que recibe por sus depósitos sino la facilidad con la cual puede hacer retiros, la seguridad que le ofrece la institución y por qué no las facilidades para hacer pagos con dichos fondos por varios canales

Bajo esta premisa, es importante realizar un análisis de que la alta concentración dentro de un mercado no necesariamente tiene que estar relacionado con un abuso de poder dentro de un mercado especifico, dado que cabe la posibilidad que el llamado Regulador debe actuar con el fin de estabilidad la situación en pro del depositante o deudor. Por lo tanto, los reguladores deberían entender cómo funcionan los sectores y como pueden fomentar la competencia entre ellos bajo su supervisión generando mayor bienestar al ecosistema financiero (Moron, Tejada y Villacorta, 2010).

En el Perú, la Superintendencia de Banca, Seguros y AFP es el organismo encargado de la regulación y supervisión del sistema financiero, de seguros y del sistema privado de pensiones. El cual tiene como objetivo preservar los intereses de los depositantes, de los asegurados y de los aportantes al SPP (SBS, 2018). Dado que es el organismo que vela por un correcto funcionamiento del sistema financiero y evitar algún "desorden" o "falla" del mercado, los bancos deben regirse bajo la Ley General del Sistema Financiero y del Sistema de Seguros y Orgánica de la SBS.

Dicha ley permite propender al funcionamiento de un sistema financiero y un sistema de seguros competitivos, sólidos y confiables, que contribuyen al desarrollo nacional (SBS, Normativa SBS, 2018). La presente permite mostrar a la SBS como órgano rector y supervisor del sistema financiero y excluye a los banco o entidades financieras estatales de su supervisión (Agrobanco, COFIDE; entre otros.). Bajo dicha ley orgánica, el sistema financiero debe funcionar con una alta competitividad y manteniendo las diversas fallas de mercado en lo mínimo posible para así seguir fortaleciendo la economía del país y poder contribuir de una mejor manera al bienestar social.

Adicionalmente, es importante observar mediante data cuantitativa, que tan concentrada se encuentra el sector de la banca múltiple en el país. Para ello se tomarán 
en cuenta dos indicadores económicos de medición de concentración: El Indicador Herfindalh y el Indicador C4. Ambos permiten realizar mediciones en los pesos relativos de los participes de un mercado y con ello poder ver el grado de concentración en dicho sector.

El Índice Herfindalh-Hirschman (HHI) es una medición empleada en el estudio económico que se centra en los niveles de concentración existentes en los mercados. Es decir, cuántas empresas operan en dicho sector y su poder que cada uno tiene dentro del mismo (Economipedia, 2018). La forma mediante la cual se realiza esta medición es sumando los cuadrados de las cuotas de mercado de las empresas en un determinado mercado. En términos convencionales. Un índice HHI superior a 1800 generalmente se considera como evidencia de un mercado altamente concentrado.

Tomando en cuenta la data proporcionada por la SBS, se puede observar que a junio 2018 el índice HHI para el subsector de créditos en el sistema bancario asciende a 1991, mientras que en depósitos totales es de 1941 y de total de tarjetas de crédito de 1947. Dado estos resultados, se puede mencionar la evidencia de una alta concentración en el sistema financiero peruano.

Para continuar con el análisis, se observará los resultados de la prueba C4. Dicho índice, permite ponderar el porcentaje total del mercado que está siendo distribuido por las principales 4 empresas líderes. Es una herramienta útil para comprobar la posible concentración que podría estar originándose en un mercado, más no necesariamente la falta de competitividad en él. Al momento de analizar, observamos que el índice $\mathrm{C} 4$ arroja un $82.92 \%$ para créditos directos, $81,57 \%$ para depósitos y $78.11 \%$ para el mercado de tarjetas de crédito. Se observa una clara tendencia a través del periodo de investigación en la cual los principales bancos líderes en el Perú son: Banco de Crédito del Perú, BBVA Banco Continental, Scotiabank Perú e Interbank Perú. Adicionalmente, si realizamos un análisis únicamente de la participación de los dos bancos líderes (BBVA Continental y el Banco de Crédito del Perú) observamos que tienen una participación conjunta mayor al $50 \%$.

Ahora que tenemos una perspectiva general de la banca múltiple en el Perú y de la concentración bancaria que esté presente, es importante plantear la siguiente pregunta: ¿Mayor concentración implica una menor competencia? Si bien es cierto se han realizado extensas investigaciones económicas a través del tiempo para evidenciar si hay alguna 
relación causa efecto entre ambas variables, hay otros elementos que entran en juego al momento de determinar la composición de un mercado (Moron, Tejada y Villacorta, 2010). Ahora bien, cabe la posibilidad de la existencia de un abuso de poder dentro de un mercado concentrado, es importante aclarar el rol crucial que puede tener un ente regulador para evitar las fallas de mercado y que podría traer consigo una mayor competitividad dentro de este.

Partiendo desde un punto inicial, podemos mencionar que las concentraciones de un mercado pueden estar establecidas no por el número de empresas que conforman un sector principal del mercado, sino también por las barreras de entrada. Tal y como lo afirma Demsetz en una conversación con Schmidt (Demsetz, 1976), lo importante no es la cantidad de competidores que hay en un mercado, sino la facilidad en la entrada y salida de ellos. Esto puede producir que los niveles de competitividad entre ellos varíen de sectores distintos. De la misma manera que un sector con mayores/menores entradas, ya sea por tamaño, establecimiento o perfil de los agentes consumidores (como en el caso del sistema financiero peruano) determina la cantidad de competidores totales, es importante observar el manejo de los costos y la eficiencia.

Investigaciones afirman que los altos niveles de concentración pueden ser resultado que las firmas más eficientes tienen la facilidad de crecer que sus contrapartes menos eficientes dado un mejor control de gastos y mejoras en temas de productividad (Demsetz, 1976). Esto parte de la teoría de las economías de escala, en las cuales las empresas al momento de expandirse pueden conseguir reducir sus costos medios y con ello obtener mejores márgenes de ganancias y poder ser más eficientes frente a otros competidores. Al darse la posibilidad de poder crecer gracias a las economías de escala, dicha empresa puede ofrecer un mejor servicio a sus consumidores y con ellos crecer a nivel de mercado y tener más poder en este.

Dado que la eficiencia es producto de mejora de procesos en vista de tener una mayor competitividad, podemos inferir que la concentración dentro de un mercado en ocasiones es a consecuencia de la competitividad en el mismo que induce a las empresas más eficientes a ser las líderes de estas. Levine (Levine, 2000) encontró que a nivel internacional no hay una relación negativa entre el desarrollo financiero y el grado de concentración del sector. En evidencia que existen más variables que interactúan de una manera más compleja dentro del ecosistema financiero, la simple implicancia de que una 
mayor concentración bancaria va a desarrollar menores niveles de competitividad y bancos menos eficientes es inválida.

\subsubsection{Impacto de la concentración al consumidor}

Por otro lado, un punto importante a evaluar es el rol que la concentración en mercados puede transmitir al consumidor. Desde un punto de vista general, la concentración en mercados puede darse debido a que se trata de un mercado duopolio, oligopolio o inclusive mercados en las cuales han derivado en situaciones monopólicas dado las fusiones o adjudicaciones que pueden ocurrir entre las empresas participantes. Partiendo desde la teoría económica establecida, el problema con los monopolio y oligopolios es que suelen abusar de su posición de líderes y aumentan sus precios de cara al consumidor de forma que pueden maximizar sus ganancias al alejar el precio del costo medio de su producción. Sin embargo, al momento de revisar las situaciones que se presentan en distintos mercados, se observa que no necesariamente se da este caso. De igual manera, un fenómeno que puede ocurrir es la aparición de los mercados de competencia monopolística.

La competencia monopolística es un tipo de mercado imperfecto en el cual existe un número de vendedores que ejercen cierto tipo de poder para poder influir en el precio del producto que ofrecen a los consumidores (Economipedia, Competencia Monopólistica, 2018). El poder de mercado se ve reflejado en la especialización o diferenciación que pueden ofrecer al producto que venden, de tal manera que esto les va a permitir ser más atractivos o menos atractivos a ojos del consumidor. Todo esto se puede ver reflejado en la competitividad de un mercado, el cual va a determinar la evolución en largo plazo de los competidores y del consumidor. Al mismo tiempo, una característica importante es que suele tener una mayor cantidad de vendedores $\mathrm{u}$ ofertantes en la composición de dicho mercado, sin esto evitar la existencia de dos o tres empresas principales que tienen un mayor poder de mercado que otras empresas, estas últimas pasando al rol de "empresas seguidoras".

Ahora bien, al analizar de manera más específica el sistema bancario en el Perú, una pregunta válida sería observar si es un mercado oligopolio o se trata justamente de un mercado de competencia monopolístico. Intentar categorizar el mercado en cualquiera de estos tipos de competencia imperfecta sería válido por las características que ofrecen, 
sin embargo, se puede inclinar más a mencionar que la competencia monopolística en el indicado para el sistema bancario peruano.

Si bien es cierto existe una tasa de referencia fijada por el BCRP de manera diaria para las operaciones pasivas y activas de los bancos, son estos últimos los que se encargan a definir sus propias tasas a ofertar de acuerdo con lo que necesiten su público objetivo, siempre tomando en cuenta lo mencionado por el Banco de Reserva (no son "precioaceptantes" de manera absoluta). Es en esta diferenciación que ofrece cada banco lo que permite al consumidor tener un abanico de opciones al momento de tomar decisiones que no sólo se limitan a la menor/mayor tasa, sino también otros aspectos como calidad de servicio, alcance de red, condiciones crediticias, etc. (producto diferenciado). Además de esto, existen una cantidad importante de participantes que no estaría dentro de lo permitido para llamar al mercado como oligopolio (aproximadamente la cifra de bancos en el Perú se ha mantenido entre 14-16 bancos en los últimos años) y finalmente cuenta con 4 bancos que se reparten poco más del $80 \%$ del mercado total, se puede ver la figura de un comportamiento monopolístico que se ha mantenido de forma continua en la última década.

Dado que la tendencia en algunos mercados marcha en dirección que los participantes de un mercado sean pocos en cantidad; ejemplificado por las fusiones y adquisiciones de empresas líderes frente a sus competidoras menos eficientes e incluso en problemas financieros, entran a jugar otros elementos externos que disminuyen el efecto negativo que podría traer una concentración de empresas dentro de un mercado.

Por ejemplo, en Estados Unidos, recientemente se dio el importante caso de la adquisición-fusión de Rite Aid con Walgreen Boots, ambas las cadenas farmacéuticas más grandes del país. Dicha megafusión traería un ambiente de monopolización que podría afectar negativamente a los consumidores, dada la característica del mercado, la volatilidad del precio de fármacos es un tema bien delicado para la sociedad y puede afectar significativamente el bienestar global de una población.

Sin embargo, el gobierno americano cuenta desde finales del siglo XIX con la denominada Ley Sherman o Sherman Anti-Trust Act, la cual, mediante el poder constitucional del congreso, poder regular los comercios interestatales y faculta al Departamento de Justicia a intervenir en caso se muestren conductas anticompetitivas o indicios de monopolización en un mercado (OurDocuments.gov, s.f.). Es con dicha ley 
que el gobierno estadounidense en múltiples oportunidades ha llegado a dilatar, suspender y alargar los procesos de fusión de algunas importantes empresas en sus respectivas industrias. Entre los casos más resaltantes a través de la historia se encuentran empresas como la American Tobacco Company, la empresa de comunicaciones AT\&T e inclusive la gigante tecnológica Microsoft Corp. En consecuencia, al momento de intentar realizar la fusión entre las empresas farmacéuticas, dicho acuerdo tuvo muchas trabas por las leyes antimonopolio del gobierno americano y llevó a la compra de la mitad de las tiendas de Rite Aid por parte de Walgreen en vez de la compra total de la empresa (Thomas, 2017).

Adicionalmente a las leyes o regulaciones que un gobierno puede implementar para la regulación de los mercados y mantener los niveles de bienestar adecuados para la sociedad, existe también los entes reguladores que pueden crearse para poder supervisar el desarrollo de sus participantes y evitar fallos en el mercado. Por ejemplo, el sector de telecomunicaciones en el Perú está conformado por un oligopolio de pocas empresas participantes ( Telefónica, Claro, Bitel, Americatel Perú, entre otras), existe el organismo denominado Osiptel, Organismo Supervisor de Inversión Privada en Telecomunicaciones, el cual se encarga de promover la competencia del mercado de telecomunicaciones, calidad del servicios de telecomunicaciones y el empoderamiento del usuario; de manera continua, eficiente y oportuna (OSIPTEL, 2018). Dicho organismo, al igual que la SBS para el sistema financiero del Perú, se encarga de Regularizar, fiscalizar, normar y supervisar la actividad del sector de telecomunicaciones de modo tal que los consumidores tengan un nivel de bienestar aceptable.

Finalmente, es inclusive el consumidor quien también tienen un rol fundamental para al conformación de los oligopolios y de las adquisiciones de las empresas. Ellos mismos determinan las preferencias al momento de elegir una marca frente a otra por distintas variables que le sirvan de atractivas frente a sus competidores y les permite crecer dentro del mercado. Del mismo modo, dado a la presencia de un ente regulador de las grandes empresas, los consumidores son quienes tienen un poder aun más importante sobre el precio (en el caso concreto del sistema financiero las tasas de interés) que estarán ofreciendo las empresas del mercado a fin de poder satisfacer las necesidades de ellos y poder captar su interés en trabajar con ellos. 


\subsubsection{Crecimiento de las Cajas de Ahorro y Crédito en el sistema financiero}

Las Cajas de Ahorro y Crédito son un conjunto de instituciones financieras no bancarizadas que son parte del sistema financiero en el Perú y que están bajo regularización de la SBS, al igual que la banca múltiple. Son entidades de crédito de forma similar de los bancos, cuya especialidad se encuentra en brindar operaciones de financiamiento a las pequeñas y microempresas (Comparabien, 2018). Asimismo, también cuentan con la protección del Fondo de Depósito de Seguros de la misma manera que lo tienen las instituciones bancarias. En el Perú, existen dos tipos principales de Cajas: las Cajas Municipales y las Cajas Rurales.

Fueron creadas durante la década de los años ochenta eran y en un primer momento eran exclusivas de los gobiernos municipales y rurales en donde fueron fundadas y en sus dos denominaciones tuvieron como objetivo principal incentivar la descentralización del sistema financiero y permitir un mayor acceso a la población a los servicios financieros privados. Con el paso del tiempo se ha visto un crecimiento importante en su consolidación dentro del sistema financiero y se afirman como un sistema que contribuye a la descentralización de los servicios financieros alrededor del país (SBS, SBS informa, 2017).

Asimismo, a junio del 2018, el sistema financiero tiene dentro de su conjunto a 12 Cajas Municipales y 6 Cajas Rurales de Ahorro y Crédito. Las instituciones microfinancieras no bancarias (CM, CRAC y Edpyme) el 7,18\% del total de activos del sistema financiero peruano con S/29,490 millones de soles (Caja Municipal: S/25,388 millones, la Caja Rural de Ahorro y Crédito: S/1,820 millones y Edpyme: S/2,281 millones) (SBS, 2018). 
Tabla 5.2

Activos de sistema financiero en millones de soles

\begin{tabular}{lccc} 
& jun-16 & jun-17 & jun-18 \\
\hline Empresas bancarias & 348305 & 353171 & 367181 \\
Empresas financieras & 11413 & 12313 & 13738 \\
Instituciones microfinancieras no bancarias & 22579 & 26266 & 29490 \\
$\quad$ Cajas municipales (CM) & 19721 & 22740 & 25388 \\
Cajas rurales de ahorro y crédit (CRAC) & 1250 & 1528 & 1820 \\
$\quad$ Enfidades de desarrollo de la pequeña & 1608 & 1999 & 2281 \\
y microempresa (Edpyme) & & & \\
Empresas de arrendamiento financiero & 468 & 392028 & 410686 \\
\hline SISTEMAFINANCIERO & 382765 & &
\end{tabular}

Fuente: Superintendencia de Banca, Seguros y AFP, SBS (2018).

Se observa un crecimiento importante en la participación de las cajas dentro del sistema financiero, el cual ha venido sosteniendo en los últimos tiempos. En Setiembre del 2008, las Cajas Municipales tenían un total de S/6,539 millones en activos mientras que las Cajas Rurales S/1,290 millones. De igual manera, se observa una tendencia importante de aumento de activos dentro del sistema financiero, producto no solo de la época de bonanza que justamente estaba atravesando el país sino también por la modernización y descentralización que se empezó a incentivar por las instituciones financieras.

De la misma manera, se observa con los niveles de colocaciones directas que las IMFNB (Instituciones Microfinancieras no Bancarias) a través de la última década se han visto aumentadas por la mayor flexibilidad de las instituciones frente a la banca tradicional. Según informes de la SBS, en Setiembre 2008, el nivel de colocaciones directa alcanzaba la cifra de S/7,239 millones; mientras que, a junio 2018, la cifra ha aumentado hasta alcanzar los S/23 807 millones (SBS, Evolucion del Sistema Financiero, 2018).

En vista de la importante evolución positiva del subsistema de las IMFNB, queda por siguiente preguntarse el porqué de su crecimiento continuo en el Perú. Generalmente, las cajas presentan una cartera de productos que son atractivos para los consumidores (Gestión, 2017). Esto se fundamenta en ofrecer una tasa de interés más atractiva para los consumidores que deseen tener una CTS y depósitos de plazo fijo de las que podrían encontrar yendo a la banca tradicional. De igual manera, suelen tener una tasa menor al momento de brindar servicio de endeudamiento financiero que los bancos tradicionales. 
Dando un ejemplo concreto, utilizando la plataforma web Comparabien.com podemos comparar la solicitud de un préstamo personal de S/10,000 soles a 12 meses obtendríamos la siguiente información:

Tabla 5.3

Comparación tasas activas de bancos vs CAC

\begin{tabular}{|l|l|l|}
\hline \multicolumn{1}{|c|}{ Institución Financiera } & \multicolumn{1}{c|}{ Pago Total } & $41.20 \%$ \\
\hline BBVA Continental & $\mathrm{S} / 12,141.00$ & $45.00 \%$ \\
\hline Interbank & $\mathrm{S} / 12,179.00$ & $41.00 \%$ \\
\hline BCP & $\mathrm{S} / 12,070.00$ & $39.00 \%$ \\
\hline Scotiabank & $\mathrm{S} / 11,983.00$ & $26.82 \%$ \\
\hline Caja Arequipa & $\mathrm{S} / 11,347.00$ & $36.28 \%$ \\
\hline Caja Metropolitana & $\mathrm{S} / 11,772.00$ & $51.72 \%$ \\
\hline CRAC Raíz & $\mathrm{S} / 12,458.00$ & \\
\hline
\end{tabular}

Fuente: Comparabien, (2018)

Elaboración propia

De la misma manera, podemos observar un comportamiento similar al momento de comparar un depósito a plazo de S/50,000 soles a 360 días:

Tabla 5.4

Comparación tasas pasivas de bancos vs CAC

\begin{tabular}{|l|l|l|}
\hline \multicolumn{1}{|c|}{ Institución Financiera } & \multicolumn{1}{c|}{ Ganancia Aproximada } & \multicolumn{1}{c|}{ Tasa de Interés TEA } \\
\hline BBVA Continental & $\mathrm{S} / 675.00$ & $1.35 \%$ \\
\hline Interbank & $\mathrm{S} / 700.00$ & $1.45 \%$ \\
\hline BCP & $\mathrm{S} / 1,000.00$ & $2.00 \%$ \\
\hline Scotiabank & $\mathrm{S} / 1,000.00$ & $2,00 \%$ \\
\hline Caja Los Andes & $\mathrm{S} / 2,950.00$ & $5.90 \%$ \\
\hline Caja Trujillo & $\mathrm{S} / 2,850.00$ & $5.70 \%$ \\
\hline CRAC Raíz & $\mathrm{S} / 3,200.00$ & $6.40 \%$ \\
\hline
\end{tabular}

Fuente: Comparabien, (2018)

Elaboración propia 
Sin bien es cierto una de las causantes de que el consumidor se vuelva adverso de invertir su dinero en las instituciones no bancarias es la seguridad de que este no peligre o se pierda ante una eventual corrida financiera; cabe recordar que todas las instituciones están regularizadas por la SBS y parte de su directorio esta compuesto por representantes del municipio, de la sociedad civil y COFIDE (SBS, SBS informa, 2017).

Asimismo, es importante mencionar que las cajas nacieron justamente para poder llegar el sistema financiero a las poblaciones más lejanas y rurales en las cuales la banca tradicional no contaba con una infraestructura establecida en modo de red de agencias o cajeros automáticos. Sin bien es cierto el contexto en el cual nacieron estas instituciones financieras ha cambiado (SBS, SBS informa, 2017) y las lleva a la necesidad de innovar cada vez más y ser más competitivos con sus márgenes para poder mantener el posicionamiento alcanzado, se han vuelto una alternativa importante para la población como una alternativa segura para rentabilizar sus fondos o buscar una mejor forma de endeudamiento.

\subsubsection{Rol de los bancos secundarios}

Tal y como se mencionó anteriormente en el presente trabajo de investigación, la banca múltiple en el Perú está concentrada en un $80 \%$ aproximadamente entre cuatro bancos líderes: BBVA Continental, Banco de Crédito del Perú, Interbank y Scotiabank Perú. Esto quiere decir que, dentro del universo financiero, hay 12 bancos quienes se reparten el restante 20\%. Al 31 de agosto del 2018, la repartición de los créditos directos es la siguiente: 
Tabla 5.5

Participación créditos directos

\begin{tabular}{|l|c|c|}
\hline Empresas & Monto & Participación \\
\hline B. de Crédito del Perú & $85,010,375$ & 33.00 \\
\hline B. Continental & $52,716,891$ & 20.47 \\
\hline Scotiabank Perú & $45,087,992$ & 17.50 \\
\hline Interbank & $30,350,964$ & 11.78 \\
\hline B. Interamericano de Finanzas & $9,963,500$ & 3.87 \\
\hline Mibanco & $9,677,838$ & 3.76 \\
\hline B. Pichincha* & $7,031,160$ & 2.73 \\
\hline B. GNB & $3,738,453$ & 1.45 \\
\hline B. Santander Perú & $3,462,650$ & 1.34 \\
\hline B. Falabella Perú & $3,146,785$ & 1.22 \\
\hline Cibibank & $2,727,063$ & 1.06 \\
\hline B. Ripley & $1,785,218$ & 0.69 \\
\hline B. de Comercio & $1,462,460$ & 0.57 \\
\hline B. Cencosud & 719,996 & 0.28 \\
\hline B. Azteca Perú & 346,139 & 0.13 \\
\hline B. ICBC & 344,919 & 0.13 \\
\hline
\end{tabular}

Fuente: Superintendencia de Banca, Seguros y AFP, (2018)

Elaboración propia

Como se puede apreciar, bancos como el Banbif, Mibanco o Banco Pichincha (ex Banco Financiero del Perú) tienen únicamente entre un 2.70\%-3.87\% de la participación de mercado total de la banca múltiple. Dada esta evidencia, es válido preguntar cuál sería el rol que cumplen dichos bancos dentro del ecosistema financiero; si de alguna manera por el "core-bussiness" definido están enfocados a un tipo de mercado específico o alguna adaptación que hayan realizado que les permita ser rentables dentro del sistema y no tener necesidad de salir.

Por ejemplo, en el caso del Banbif, el cual ocupa el quinto lugar con 3.87\% de participación en el sector, indican que tienen un nicho específico de clientes específicos que les permite seguir siendo competitivos dentro del mercado. Según una entrevista brindada en el diario El Comercio por Juan Carlos García Vizcaíno, gerente general del banco, el ADN del Banbif en el Perú se encuentra en los sectores medio y alto del mercado (Hurtado, 2018). De la misma manera, García comenta que se están enfocando principalmente al financiamiento de las empresas de comercio exterior, como también teniendo una conexión más cercana con las personas naturales. “...Es donde queremos crecer más. Primero, Mediana y Gran Empresa. Es donde tenemos el ADN del banco y 
tenemos mayor ventaja ahí." Finalmente agrega: "Y por el lado minorista, en esos segmentos, tenemos un gran espacio para crecer" (Hurtado, 2018).

El Banbif de esta manera quiere enfocarse en ser un banco el cual se convierta en el perfecto aliado para las empresas de segmento medio y alto. Un banco que no necesariamente sea grande y masivo pero que sí les permita tener toda la gama de productos que requiera a su disposición necesaria, haciendo bastante hincapié en la transformación digital que el mercado lo requiere.

El nicho de mercado que nos hemos fijado en los últimos años es el de la banca Empresa y Corporativa", añade Diego Solano, Analista de Riesgos de Banca Negocios en el Banbif, "esto nos permite brindar un servicio premium que nos amerite una tasa mayor. (D. Solano, comunicación personal, 16 de octubre, 2018).

Asimismo, uno de los principales objetivos para que la rentabilidad del banco se mantenga de manera importante es controlar los niveles de morosidad, lo cual les va a permitir seguir siendo rentables, dado que no cuentan con la misma espalda financiera que un banco grande, esto les permitirá manteniendo los ratios y metas requeridas por su casa matriz. "Gracias a las políticas de riesgo más estrictas que manejamos en estos momentos, nos ha permitido tener una cartera de clientes con mejor carácter y de esta manera tener colocaciones menor agresivas y asegurar nuestras metas” finalizó Solano.

En el caso del Banco Pichincha o anteriormente denominado Banco Financiero, ellos tienen un también un público específico que les ha permitido poder subsistir dentro del mercado peruano gracias a la condición del Perú como lugar estratégico para su casa matriz el Grupo Pichincha. En los dos últimos años, el banco ha pasado por una reestructuración realizando una mejora en sus procesos operativos y enfocándose en nuevos objetivos con miras a mejorar su posicionamiento en el sistema financiero como también sus ratios de cumplimiento. Dicho proceso culminó con el cambio de nombre a Banco Pichincha en el 2018, llamándose de la misma manera que su matriz en Ecuador. El banco se enfoca principalmente en segmentos específicos de personas jurídicas y microfinanzas, en los cuales le ha permitido tener un crecimiento en sus niveles de rentabilidad, eficiencia operativa y menores gastos financieros (Rating, 2018).

Ahora bien, si bien es cierto el banco presenta un abanico de productos financieros que abarcan los segmentos de Banca Mayorista ( Corporativa, Mediana y Gran Empresa) , Banca Minorista y Microfinanzas, el segmento principal es la banca persona y los 
créditos empresariales de nicho con un ticket promedio alrededor de 88 mil soles (Rating, 2018), el cual se ubica dentro del rango de las medianas y grandes empresas, mismo nicho que los bancos de igual magnitud (pj: el Banco Banbif) suelen colocarse dentro de la banca múltiple peruana exceptuando los cuatro grandes bancos. Esto se debe al plan estratégico de cara al 2020 que el banco planea seguir el cual se enfoca en la realización de la gestión del negocio core, de manera que se determinen los mejores productos acorde a cada segmento del banco y de cara a mejorar la experiencia del cliente con el banco.

De igual manera se encuentra el Banco Mibanco, el primer banco privado dirigido a micro y pequeña empresa, quien ocupa el puesto $6^{\circ}$ en el ranking de Créditos totales dentro del sistema de Banca múltiple con S/9,671 miles de soles a Julio del 2018. Sin embargo, al observar la distribución del sistema por tipo de crédito, podemos observar que es el banco líder en el rubro de créditos a Pequeñas Empresas y Microempresas, con un monto de 5,571 miles de soles (37.91\% de participación) y 2,805 miles de soles ( $81.57 \%$ de participación) respectivamente. Esto le ha permitido tener más de 300 agencias a nivel nacional y más de 950 mil clientes de créditos en el sistema financiero.

El banco contemporáneo nace a partir de la adquisición en 2014 de la Financiera Edyficar (subsidiaria del Credicorp) realizada a Mibanco, Banco de la Microempresa S.A. en la cual se adjudicó más (Equilibrium, 2018) del 60\% de su capital social por medio de acciones. A fin de dicho año y a inicios del 2015, se finiquitó el traslado de un bloque patrimonial de Edyficar comprendido por activos y pasivos a ser absorbidos por Mibanco, de manera tal que el banco ahora pasar a ser una subsidiaria del Banco de Crédito del Perú y parte del grupo Credicorp.

La cartera de Mibanco, producto de la especialización que se le ha brindado dentro del grupo Credicorp y de la participación que tuvo de la Financiera Edyficar, esta colocada como la empresa de microfinanzas del holding peruano, de manera tal que tiene un core bussiness completamente definido y especializado desde un primer momento. Si bien es cierto la cartera de colocaciones que maneja el banco también atiende a otros segmentos como lo haría sus similares en el sistema financiero, la distribución de sus carteras se ve principalmente repartido entre la Pequeña Empresa y el sector de Microempresa (Equilibrium, 2018), como se observa en el siguiente cuadro: 
Figura 5.1

Evolución de la cartera de colocaciones según tipo de crédito

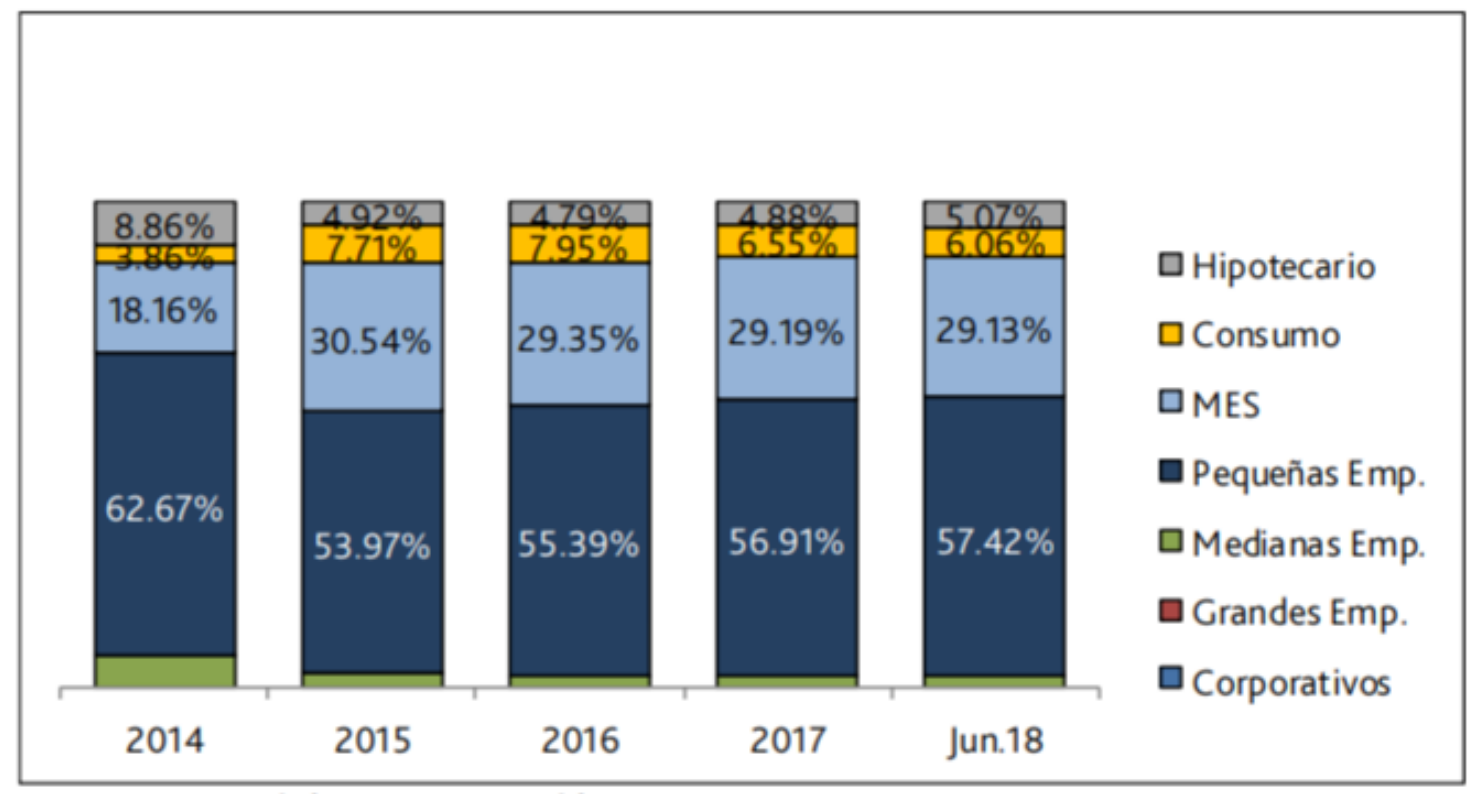

Fuente: Superintendencia de Banca, Seguros y AFP, (2018)

Esto se debe a que el objetivo de Mibanco no solo es otorgar un financiamiento a su segmento core ( micro y pequeña empresa) facilitando así la inclusión financiera del consumidor peruano, sino también servir de guía económico con el cliente y tener una relación a largo plazo que le permita estar presente dentro de su desarrollo empresarial y el crecimiento de su empresa (ASOCIADOS, 2018).

\subsection{Análisis econométrico de la información}

La pregunta principal dentro del presente estudio de caso es analizar si la concentración en el sistema bancario en el Perú conlleva a un mayor grado de competencia por parte de las entidades partícipe. Para esto se realizará un análisis econométrico mediante la técnica de mínimos cuadrados ordinarios en la cual se tomará en cuenta la relación de los depósitos totales de los 2 principales bancos en el sistema bancario con las tasas de interés activas promedio en moneda nacional del resto de bancos partícipes. El análisis se realizará con data mensual del 2012 al 2017.

Para poder delimitar el modelo a especificar econométricamente, la variable dependiente será la sumatoria de los depósitos de los principales 2 bancos líderes en el Perú; el Banco de Crédito del Perú y el BBVA Continental, las cuales se encuentran en miles de soles tal y como lo reporta la SBS. 
Si bien es cierto el índice C4 arrojó un porcentaje de concentración alrededor de $80 \%$ en los líderes del sistema bancario, se estará trabajando solamente con los depósitos de los principales líderes de este, quienes igual mantienen un importante porcentaje de mercado entre ellos (más del 50\%), dado que igual podemos observar el comportamiento frente a la tasa de intereses no solamente de las empresas seguidoras, sino también de las "cuasi-líderes" que se encuentran dentro del top 4 en el sistema (Interbank y Scotiabank Perú).

Las variables independientes, corresponden a las tasas de interés en moneda nacional promedio de los bancos restantes que conforman el sistema de la banca múltiple en el Perú. Dado que solamente se está utilizando los depósitos de los principales dos bancos como variable dependiente, las tasas de interés de los otros integrantes del conjunto $\mathrm{C} 4$ se tendrán en cuenta para medir si existe una competitividad entre las tasas que brindan los bancos frente al comportamiento de los bancos líderes. Asimismo, específicamente se está empleando las tasas promedio del rubro consumo, el cual según la web de la SBS engloba las siguientes categorías: Tarjetas de Crédito, Préstamos Revolventes, Prestamos no revolventes para automóviles y Créditos pignoraticios. Se utilizó esta categoría de tasas de interés dado que permite englobar una mayor cantidad de bancos que no necesariamente participan entras categorías de colocaciones por su público objetivo.

Para poder responder el objetivo principal del tema de investigación; comprobar si la concentración de bancos en el Perú ha traído consigo una mayor o menor competencia entre sus partícipes; se estará realizando a través de la técnica econométrica de Mínimos Cuadrados Ordinarios bajo un modelo de regresión lineal. En un modelo de regresión lineal lo que se trata es que la variable de respuesta es una función lineal de "N" variables explicativas que tienen alguna relación hacia ella dependiendo del signo que dichas variables muestren al momento de aplicar la regresión. Se estará empleando el programa econométrico Stata para poder realizar las regresiones correspondientes

Mediante el siguiente modelo, se intentará buscar la relación que se encuentre entre las tasas de interés de los bancos con los depósitos totales de los bancos líderes, siguiendo los principales tres supuestos a cumplir:

- La varianza de los errores debe ser homocedástica. 
- Las variables explicativas deben ser ortogonales a los residuos sin compartir información entre ellas.

- Los errores no deben estar correlacionados entre sí.

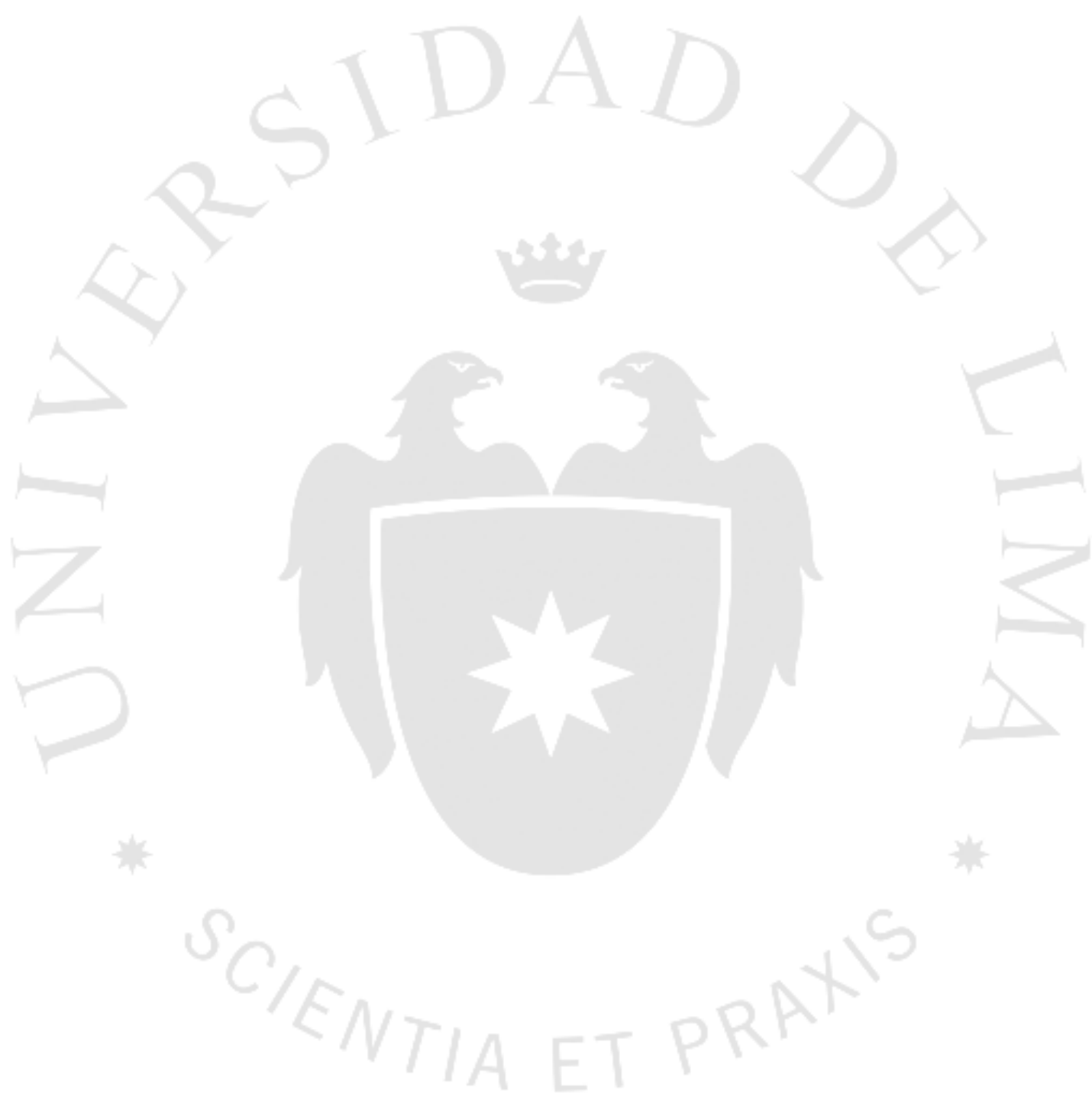




\section{DESCRIPCIÓN DEL CASO}

El presente estudio de caso tiene como objetivo principal el estudio de la concentración bancaria en el sistema de banca múltiple en el Perú para los periodos 20122017. Para ello, se desarrollarán los objetivos principales y secundarios anteriormente planteados y estos serán trabajados a partir de un modelo econométrico y la investigación respectiva a la teoría económica y otras investigaciones pertinentes.

En cuanto al modelo econométrico a emplear, se realizará una regresión lineal de Mínimos Cuadrados Ordinarios (MCO) utilizando la data mensual entre los periodos 2012-2017 del total de colocaciones de los principales dos bancos líderes del sistema de banca múltiple y las tasas de interés activas en moneda mensual promedio en el rubro de consumo de los bancos restantes del sistema bancario. La presente data ha sido recolectada de la página web de la SBS en octubre del 2018.

De la misma manera, se desarrollará a través de la investigación de teoría y recolección de datos, el rol que cumplen los bancos "secundarios" dentro del sistema financiero peruano, esto con el fin de explicar sus sostenibilidad en el mercado a pesar de tener una participación de mercado pequeña.

Del mismo modo, se desarrollará el impacto que tienen las Cajas de Ahorro y Crédito dentro del sistema financiero y cual es su relación con la oferta generada por los bancos en la prestación de servicios financieros. 


\section{ANÁLISIS Y DISCUSIÓN DEL CASO}

Recapitulando lo mostrado en anteriores secciones del presente estudio de caso, el objetivo principal a trabajar es si la concentración del sistema bancario que se mantiene en la actualidad presenta permite o no permite el desarrollo de la competitividad en dicho marcado. Para ello no solamente se estará revisando la información encontrada en investigaciones pasadas sino también mediante un modelo de regresión lineal MCO.

Luego de repasar la información investigada en la sección anterior, se puede observar que la concentración de un mercado no necesariamente se da a causa de una falla de mercado o por el abuso de poder que tengan alguna de las firmas, sino también en términos de eficiencia que les ha permitido captar una mayor participación de mercado. La competencia trae consigo que las empresas puedan realizar un mayor esfuerzo en ofrecer una mejora en sus servicios a sus consumidores de manera que puedan ofrecer un producto diferenciado a su competencia y esto repercute en mayores ingresos y por ende en un mayor grado de participación del mercado.

Para fundamentar dicha afirmación desde el aspecto econométrico, se realizará la regresión lineal en la cual se esperaría encontrar una relación directa entre las tasas de intereses de los bancos pertenecientes y las colocaciones realizadas de los bancos líderes en el Perú. Esto mostraría que al momento de tener unas tasas de interés más altas los bancos del sistema financiero, los bancos líderes ganarían mayores captaciones puesto que tienen unas tasas de interés menores que les permite ser más competitivos al resto y seguir creciendo dentro del mercado.

Para dicho modelo se tomará en cuenta data mensual entre los periodos 20122017 de las colocaciones totales de los bancos y de sus tasas de interés activas en moneda nacional en promedio. Esta información fue extraída de la pagina web de la SBS de carácter público.

Entrando al modelo en específico, se realizaron diversas pruebas y regresiones entre las variables independientes con la variable dependiente (suma de las colocaciones de los principales bancos líderes) y tomando en cuenta la cantidad de información y la significancia de los coeficientes o los signos se empezaron a descartar alguna de ellas. Se tuvo como principal requisito que los bancos tengan la información completa en el periodo seleccionado, puesto que durante esos años hubo el ingreso de algunos bancos al 
sistema financiero peruano y la salida de otros, por lo que no se contaba con mucha información dentro del tiempo de estudio especificado. De la misma manera, se fue quitando y agregando variables conforme la significancia general y específica del modelo lo permitía. Finalmente, realizando las pruebas preliminares para verificación de modelos MCO, se fue perfilando el posible modelo para desarrollar el objetivo principal que fue planteado. A continuación, se presenta la ecuación del modelo econométrico:

$$
C T_{t}=I B K_{t}+S C B K_{t}+B P I C H_{t}+\text { MIBANCO }_{t}+C E N C O S U D_{t}+F A L A B_{t}+\mu
$$

En la cual las variables que la conforman son las siguientes:

\section{Tabla 7.1}

Variables de estudio

\begin{tabular}{|c|c|}
\hline Variable & Definición: \\
\hline$C T_{t}$ & $\begin{array}{l}\text { Es la sumatoria de las Colocaciones Totales de los principales bancos líderes } \\
\text { del Sistema Bancario: BCP y BBVA. }\end{array}$ \\
\hline$I B K_{t}$ & $\begin{array}{l}\text { Es la tasa de intereses activa en moneda nacional promedio del banco Interbank } \\
\text { para el rubro de Consumo. }\end{array}$ \\
\hline$S C B K_{t}$ & $\begin{array}{l}\text { Es la tasa de intereses activa en moneda nacional promedio del banco } \\
\text { Scotiabank para el rubro de Consumo. }\end{array}$ \\
\hline $\mathrm{BPICH}_{t}$ & $\begin{array}{l}\text { Es la tasa de intereses activa en moneda nacional promedio del Banco } \\
\text { Pichincha para el rubro de Consumo. }\end{array}$ \\
\hline$M I B A N C O_{t}$ & $\begin{array}{l}\text { Es la tasa de intereses activa en moneda nacional promedio del Banco MiBanco } \\
\text { para el rubro de Consumo. }\end{array}$ \\
\hline$C E N C O S U D_{t}$ & $\begin{array}{l}\text { Es la tasa de intereses activa en moneda nacional promedio del Banco } \\
\text { Cencosud para el rubro de Consumo. }\end{array}$ \\
\hline$F A L A B_{t}$ & $\begin{array}{l}\text { Es la tasa de intereses activa en moneda nacional promedio del Banco Falabella } \\
\text { para el rubro de Consumo. }\end{array}$ \\
\hline
\end{tabular}

Elaboración propia 
A continuación, se muestra la tabla correspondiente a la regresión presentada para el presente estudio de caso:

Tabla 7.2

Regresión del modelo

\begin{tabular}{r|crc} 
Source & SS & df & MS \\
\hline $\begin{array}{r}\text { Model } \\
\text { Residual }\end{array}$ & $2.5977 \mathrm{e}+16$ & 6 & $4.3295 \mathrm{e}+15$ \\
$1.2016 \mathrm{e}+15$ & 65 & $1.8487 \mathrm{e}+13$ \\
\hline Total & $2.7179 \mathrm{e}+16$ & 71 & $3.8280 \mathrm{e}+14$
\end{tabular}

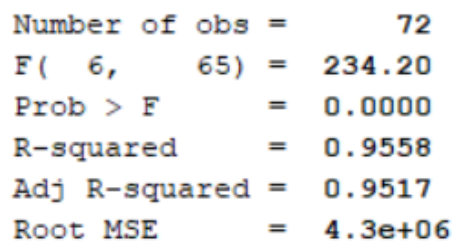

\begin{tabular}{r|rrrrrr}
\hline$y$ & Coef. & Std. Err. & $t$ & P $>|t|$ & [95\% Conf. Interval] \\
\hline ibk & 917951.3 & 111193.5 & 8.26 & 0.000 & 695882.6 & 1140020 \\
scbk & 429101.8 & 231095.2 & 1.86 & 0.068 & -32427.15 & 890630.7 \\
bpich & 667580.5 & 101483.6 & 6.58 & 0.000 & 464903.7 & 870257.3 \\
mibanco & 1347400 & 357335.6 & 3.77 & 0.000 & 633751.5 & 2061049 \\
cencosud & 103489.2 & 19777.37 & 5.23 & 0.000 & 63991.07 & 142987.3 \\
falab & 599214.2 & 141456.9 & 4.24 & 0.000 & 316705.2 & 881723.1 \\
_cons & $-7.01 e+07$ & $1.33 e+07$ & -5.25 & 0.000 & $-9.67 e+07$ & $-4.34 e+07$ \\
\hline
\end{tabular}

Elaboración propia.

Como se observa en el cuadro de la regresión realizada en Stata, vemos que los coeficientes de las variables independientes son positivos, los cual indica una relación directa frente al total de colocaciones que reciben los bancos líderes en el Perú. Esto se verifica de la siguiente manera, al aumentar en $1 \%$ la tasa de interés activa en promedio del Interbank, estarían aumentando en S/ 917,951 soles las colocaciones totales del BBVA y BCP en sumatoria, lo cual interiorizando se daría a que estos últimos ofrecen una mejor tasa (menor en este caso) gracias al respaldo financiero que dichas instituciones tienen y que les permite realizar una mayor colocación de prestamos a nivel mercado y con ello una mayor cuota de participación.

En la toma de decisiones de los bancos frente alguna propuesta de negocio potencial ya sea persona jurídica o persona natural, como también al momento de decidir las condiciones del préstamo a ofrecer, no solamente se toma en cuenta las condiciones crediticias que pueda establecer frente a garantías o medios de pago del cliente, sino también la tasa de interés. Es que, si bien existe un Pricing correspondiente al tipo de operación que toma en cuenta los gastos de fondeo a cubrir por parte de la institución bancaria, un grado importante de cara al cliente para ofrecer el precio final (o tasa de 
interés en este caso) es la oferta que la competencia esta ofreciendo para la misma situación. Esto permite al banco, para ganar una operación o captar mayor mercado, realizar un ajuste a sus niveles de tasa de interés a primera instancia o también ajustes secundarios que pueden venir de la mano de un cambio en las condiciones crediticias a tomar con el cliente, que puede ser una garantía menor o periodos de gracia en los cronogramas de pago.

Por lo tanto, podemos comprobar que efectivamente existe una competencia entre los participes del sistema bancario en el Perú a pesar de la existencia de una concentración entre los bancos líderes. Es importante recordar según lo revisado, que el órgano supervisor del sistema financiero; la SBS, es el encargado de velar por el correcto funcionamiento del mercado y ser el encargado de lidiar con las posibles fallas que podrían aparecer. Dado el tipo de sistema financiero del Perú, el cual dentro de los últimos años se ha ido fortaleciendo y disminuyendo su nivel de dolarización (comparado con la década pasada), la SBS se encarga de velar por el bienestar de los depositantes y tomadores de deuda de tal forma que las empresas líderes (y las seguidoras) tengan un comportamiento adecuado con ellos al margen de su posición y poder de mercado que tengan.

Por otro lado, en capítulos anteriores se observa que algunos bancos secundarios que conforman el sistema financiero peruano tienen estrategias específicas que les han permitido seguir dentro de la banca múltiple a pesar de tener una participación de mercado muy pequeña. Tal es el caso de los bancos Banbif y Banco Pichincha, los cuales presentan una participación dentro del sistema entre $3.5 \%$ y $2.7 \%$ cuentan con una estrategia adaptada a su core bussiness de mediana y gran empresa, que les ha permitido mantener buenos niveles de rentabilidad y seguir creciendo dentro de sus proyecciones anuales. Como se explico anteriormente, la clave de este funcionamiento radica en realizar una reestructuración de las metas del banco de tal manera que los segmentos más importantes puedan mejorar en materia de eficiencia operativa y experiencia de cliente, consiguiendo así un mayor margen de ganancia que el banco pueda rentabilidad con las operaciones que tenga y le permitan afianzar los lazos empresariales entre sus clientes en el largo plazo. Todo esto tomando en cuenta la importancia de una buena e importante control de morosidad y calidad de la cartera de colocaciones por parte de sus unidades de Créditos y Riesgos empresariales, ya que al no tener un respaldo financiero tan grande 
como otros bancos, la morosidad y los créditos atrasados suelen ser un factor muy importante para los bancos "pequeños".

Por otro lado, se encuentra el caso de Mibanco, el primer banco privado especializado para el sector de la micro y pequeña empresa. Dicha institución bancaria pertenece a uno de los holdings financieros más importantes del Perú (Grupo Credicorp) y es también la subsidiaria del Banco de Crédito del Perú, lo que le permite tener una fortaleza patrimonial que le ha contribuido a colocarse como la empresa líder en su sector específico no solo por el "know-how" de las empresas madres en materia de microfinanzas (Financiera Edyficar y el Mibanco "antiguo") sino también por tener una amplia red de agencias en todo el territorio nacional que le permite tener una mayor llegada con el consumidor.

En conclusión, se puede concluir la existencia de una alta concentración dentro de la Banca Múltiple en el sistema financiero peruano, principalmente en las colocaciones directas en donde más del $80 \%$ del total se concentra en cuatro bancos. Asimismo, se demuestra que existe una interacción entre las tasas de interés que los bancos "seguidores" utilizan frente las de los bancos "líderes" que se ve reflejado en el nivel de colocaciones directas que impacta en la participación de mercado de estos.

Tomando en cuenta que existe un organismo competente regulador del funcionamiento del sistema (SBS) que permite minimizar el impacto de las fallas de mercado producto de la concentración, podemos evidencia que esta no impide la competitividad entre empresas, sino mas bien es una consecuencia de la adaptabilidad que han tenido algunas empresas que les ha permitido tener una mejora en sus procesos y ser más eficientes para poder brindar productos más atractivos al consumidor y en consiguiente ganar participación de mercado. 


\section{RECOMENDACIONES}

Como principal recomendación al presente trabajo se podría realizar el mismo análisis econométrico tomando en cuenta individualmente los créditos colocados por cada uno de los bancos líderes de Perú con sus contra partes, tanto líderes como bancos secundarios. De esta manera se podría tener una visión más específica de la influencia que tienen otros bancos con los créditos colocados por su competencia en materia de las tasas de interés que estos ofrecen al público.

De igual manera, se podría ampliar el espectro de investigación del presente estudio de caso abarcando también los depósitos del sistema financiero, para poder comprobar el fenómeno de la concentración y competitividad entre los bancos participes no solamente en los activos sino también en el manejo de los pasivos.

Inclusive, se podría realizar una investigación más específica haciendo la división dentro del aspecto de los créditos directos de manera que se tenga información por cada tipo: Microempresa, Pequeña Empresa, Gran Empresa, Corporativo, etc. Esto permitirá ver si se replica la figura de "competitividad-concentración" en los distintos mercados de crédito de la misma manera que se observa en el mercado de créditos de consumo.

Finalmente, una recomendación adicional sería ampliar el análisis estructural del sistema bancario a nivel microeconómico. Esto es, definir de manera precisa las características necesarias para categorizar el mercado como uno de competencia monopolísticas o en su defecto un mercado oligopolio. Si bien es cierto el sistema de banca múltiple comparte características de ambos mercados, con una investigación más a fondo de este tema podría ayudar a identificar la tipología en el caso peruano. 


\section{REFERENCIAS}

Comparabien. (Octubre de 2018). ¿Qué es una Caja de Ahorro y Crédito?. Recuperado de https://comparabien.com.pe/faq/que-caja-ahorro-y-credito

Demsetz, H. (Abril de 1976). JSTOR. Recuperado de The University of Chicago Press Journals: https://www.jstor.org/stable/725320?seq=1\#page_scan_tab_contents

Echevarría, y Milagro, F. D. (2016). Concentración y Rentabilidad en la Banca Múltiple Peruana: 2001-2016. (Tesis para optar el título de Economista). Recuperada de http://dspace.unitru.edu.pe/bitstream/handle/UNITRU/8646/echevarriamarcelo_ fiorella.pdf?sequence $=1 \&$ isAllowed $=\mathrm{y}$

Economipedia. (2018). Indice Herfindahl-Hirschman. Obtenido de Economipedia: http://economipedia.com/definiciones/indice-herfindahl-hirschman.html

Cajas Municipales proyectan crecimiento de captaciones entre $16 \%$ y 18\% para 2018. (06 de Diciembre de 2017). Gestión. Recuperado de https://gestion.pe/economia/cajas-municipales-proyectan-crecimientocaptaciones-16-y-18-2018-222235

Hurtado, C. (25 de Junio de 2018). Banbif: "Podemos crecer entre 10\% y 15\% los próximos años". El Comercio. Recuperado de https://elcomercio.pe/economia/dia-1/banbif-crecer-10-15-proximos-anosnoticia-530478

Levine, R. (Enero de 2000). Bank Concentration: Chile and International Comparisons. Recuperado de https://pdfs.semanticscholar.org/9c99/53711da97ead8031a75692ff1273f447ecab .pdf

Moron, E., Tejada, J., y Villacorta, A. (Noviembre de 2010). Competencia y concentración en el Sistema Financiero del Perú . Recuperado de dhttp://repositorio.up.edu.pe/bitstream/handle/11354/356/DD1003.pdf?sequence $=1 \&$ isAllowed $=\mathrm{y}$

OSIPTEL. (2018). Misión. Recuperado de https://www.osiptel.gob.pe/categoria/misionvision-finalidad

OurDocuments.gov. (s.f.). Sherman Anti-Trust Act (1890). Recuperado de Ourdocuments: https://www.ourdocuments.gov/doc.php?flash=false \&doc=51 
SBS. (Febrero de 2017). SBS informa. Recuperado de http://www.sbs.gob.pe/Portals/0/jer/BOLQUINCENAL/20170316_BolQuincenal-N2.pdf

SBS. (2018). Acerca de la SBS. Recuperado de http://www.sbs.gob.pe/acercadelasbs

SBS. (Junio de 2018). Evolucion del Sistema Financiero. Recuperado de https://intranet2.sbs.gob.pe/estadistica/financiera/2018/Junio/SF-2103jn2018.PDF

SBS. (Junio de 2018). Evolución del Sistema Financiero. Recuperado de https://intranet2.sbs.gob.pe/estadistica/financiera/2018/Junio/SF-2103jn2018.PDF

SBS. (2018). Normativa SBS. Recuperado de http://www.sbs.gob.pe/publicaciones/normativa-sbs

Thomas, L. (. (29 de JUNIO de 2017). Walgreens scraps Rite Aid deal, to buy some stores instead. Recuperado de https://www.cnbc.com/2017/06/29/walgreensscraps-rite-aid-deal-to-buy-some-stores-instead.html 